\title{
Bilateral radial access for chronic total occlusion recanalization
}

\section{Nikola Bakracheski*, Dejan Mancheski, Elena Kovacheska, Jasmina Spaseska, Deni Razmoski}

Institute of Cardiovascular Diseases, Ohrid, Macedonia

RECEIVED:

October 27, 2018

ACCEPTED:

November 5, 2018

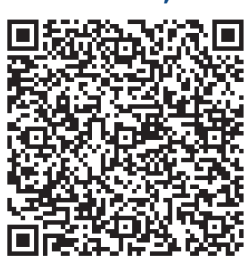

$\square$ Cardiologia Croatica 2018;13(11-12):388.
KEYWORDS: chronic total occlusion, percutaneous coronary intervention, bilateral radial access. CITATION: Cardiol Croat. 2018;13(11-12):388. | https://doi.org/10.15836/ccar2018.388 *ADDRESS FOR CORRESPONDENCE: Nikola Bakracheski, 6000 Ohrid, Macedonia. / Phone: +389-76-225-500 E-mail:nbakrac@yahoo.com

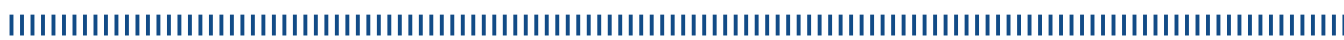

Background: Transradial access (TRA) is preferred vascular access for the most interventionalists worldwide. Distal radial access (RA) is promising technique for performing percutaneous coronary intervention (PCI), using left radial artery. ${ }^{1}$

Case report: 62-years-old female patient with effort angina was admitted to our hospital for chronic total occlusion (CTO) recanalization of proximal left anterior descending artery (LAD), after a failed attempt 2 years ago, and mid-right coronary artery stented 3 years ago. Angiogram showed $10 \mathrm{~mm}$ long occluded segment of proximal LAD, and no significant lesions of RCA and circumlex artery (Cx). We used antegrade CTO technique via right RA and simultaneous contralateral injection via left distal RA. Using 6F guiding catheter (GC), we advanced Fielder XT quide wire and Finecross microcatheter for the lesion crossing. After the failed first attempt we exchanged Fielder XT with Pilot 200 and successfully crossed the occluded segment. CTO wire was exchanged with normal workhorse wire and lesion preparation with $1.5 \mathrm{~mm}, 2.0 \mathrm{~mm}$ and $2.5 \mathrm{~mm}$ semicompliant balloons (SCB) was done. Side-branch (SB) was jailed and 3.0x48 mm drug-eluting stent (DES) deployed. At the end proximal optimization technique (POT) with 3.5x15 mm noncompliant (NC) balloon was done.

Results: Using bilateral radial access and antegrade CTO technique we restored normal coronary flow with optimal stent deployment and no SB compromising. Total procedural time was $47 \mathrm{~min}$, radiation exposure time was $29 \mathrm{~min}$, and we used $130 \mathrm{ml}$ of contrast dye. Compressive bandages were used for the hemostasis of both radial arteries and the patient was discharged at the same day.

Conclusion: Bilateral radial access is feasible and safe procedure that can be used for CTO recanalization, providing less puncture site complications and shorter hospitalization. 